\title{
Associations of malaria, HIV, and coinfection, with anemia in pregnancy in sub-Saharan Africa: a population-based cross-sectional study
}

Paddy Ssentongo ${ }^{1,2^{*}}$ D, Djibril M. Ba ${ }^{2,3}$, Anna E. Ssentongo ${ }^{2}$, Jessica E. Ericson ${ }^{4}$, Ming Wang ${ }^{2}$, Duanping Liao ${ }^{2}$ and Vernon M. Chinchilli ${ }^{2}$

\begin{abstract}
Background: Malaria and HIV are common infections in Africa and cause substantial morbidity and mortality in pregnant women. We aimed to assess the association of malaria with anemia in pregnant women and to explore the joint effects of malaria and HIV infection on anemia in pregnant women.

Methods: We used nationally representative, cross-sectional demographic and health surveys (DHS) that were conducted between 2012 and 2017 across 7 countries of sub-Saharan Africa (Burundi, the Democratic Republic of the Congo, Gambia, Ghana, Mali, Senegal and Togo). The outcome variables were anemia (defined as a hemoglobin concentration $<110 \mathrm{~g} / \mathrm{L}$ ), and hemoglobin concentration on a continuous scale, in pregnant women at the time of the interview. We used generalized linear mixed-effects models to account for the nested structure of the data. We adjusted models for individual covariates, with random effects of the primary sampling unit nested within a country.

\footnotetext{
* Correspondence: pssentongo@pennstatehealth.psu.edu; http://www.esm. psu.edu

${ }^{1}$ Center for Neural Engineering, Department of Engineering, Science and Mechanics, Penn State University, University Park, PA, USA

${ }^{2}$ Department of Public Health Sciences, Penn State College of Medicine, Hershey, PA, USA

Full list of author information is available at the end of the article
}

(c) The Author(s). 2020 Open Access This article is licensed under a Creative Commons Attribution 4.0 International License, which permits use, sharing, adaptation, distribution and reproduction in any medium or format, as long as you give appropriate credit to the original author(s) and the source, provide a link to the Creative Commons licence, and indicate if changes were made. The images or other third party material in this article are included in the article's Creative Commons licence, unless indicated otherwise in a credit line to the material. If material is not included in the article's Creative Commons licence and your intended use is not permitted by statutory regulation or exceeds the permitted use, you will need to obtain permission directly from the copyright holder. To view a copy of this licence, visit http://creativecommons.org/licenses/by/4.0/ The Creative Commons Public Domain Dedication waiver (http://creativecommons.org/publicdomain/zero/1.0/) applies to the data made available in this article, unless otherwise stated in a credit line to the data. 


\begin{abstract}
(Continued from previous page)
Results: A total of 947 pregnant women, ages, 15-49 y, were analyzed. Prevalence of malaria only, HIV only, and malaria- HIV coinfection in pregnant women was 31\% (95\% Cl: 28.5 to $34.5 \%, n=293), 1.3 \%$ (95\% Cl: 0.77 to 2.4\%, $n=13)$ and $0.52 \%(95 \% \mathrm{Cl}: 0.02$ to $1.3 \%, n=5)$ respectively. Overall prevalence of anemia was $48.3 \%$ (95\% Cl: 45.1 to 51.5\%). The anemia prevalence in pregnant women with malaria infection only was 56.0\% (95\% Cl: 50.1 to $61.7 \%$ ); HIV infection only, 62.5\% (95\% Cl: 25.9 to 89.8\%); malaria- HIV coinfection, 60.0 (95\% Cl: 17.0-92.7\%) and without either infection, $44.6 \%$ (95\% Cl: 40.7 to 48.6\%). In the fully adjusted models, malaria infection was associated with $27 \%$ higher prevalence of anemia ( $95 \% \mathrm{Cl}$ of prevalence ratio: 1.12 to $1.45 ; p=0.004$ ), and $3.4 \mathrm{~g} / \mathrm{L}$ lower hemoglobin concentration ( $95 \% \mathrm{Cl}$ : 5.01 to $-1.79 ; p=0.03$ ) compared to uninfected pregnant women. The prevalence of HIV infection and malaria-HIV coinfection was too low to allow meaningful analysis of their association with anemia or hemoglobin concentration.
\end{abstract}

Conclusion: Malaria was associated with an increased prevalence of anemia during pregnancy.

Keywords: Anemia in pregnancy, Demographic and health surveys, Hemoglobin, HIV, Malaria, Coinfection, Lowand middle-income countries, Iron supplementation, Sub-Saharan Africa

\section{Background}

Globally, 38\% of pregnant women are anemic, and rates are higher in sub-Saharan Africa at 56\%, compared with high income countries at 22\% [1]. Anemia in pregnancy is associated with an increased risk of maternal and perinatal mortality and low birth weight [2]. The long-term effects of anemia in pregnancy increase the risk of neurocognitive impairment in the offspring. Two infectious agents, human immunodeficiency virus (HIV) and Plasmodium falciparum malaria, are associated with the etiology of anemia in pregnancy in sub-Saharan Africa [3]. In 2018, the prevalence of exposure to malaria infection in pregnancy in sub-Saharan Africa was 29\% (equivalence of 11 million pregnancies) [4]. The burden was highest in West and Central African countries. Similarly, the prevalence of HIV infection in pregnant women in sub-Saharan Africa ranges between 11.6 to $22.0 \%$ in Southern Africa, 2.2 to $3.9 \%$ in Western Africa and Eastern Africa [5]. The prevalence mirrors regional-level HIV prevalence in the general population [6]. The burden of HIV and malaria in this region is one of the leading causes of morbidity and mortality for mothers and their newborns [7-9]. Due to the overlapping geographical distribution of malaria and HIV in sub-Saharan Africa, malaria- HIV coinfection is common and leads to over one million pregnancy complications per year $[10$, 11]. Such complications include low birth weight, higher rates of neonatal mortality, placental malaria infection, reduced transfer of maternal antibodies and increased risk of mother-child transmission of HIV.

In a recent cross-sectional study aimed at characterizing the prevalence of malaria in people living with HIV, the prevalence of malaria was $7.3 \%$ [12]. The prevalence was significantly higher in study participants who did not sleep in insecticide-treated bed nets, participants who were not on co-trimoxazole prophylaxis and those whose $\mathrm{CD} 4{ }^{+} \mathrm{T}$ cell count was below 200 cells/ $\mu \mathrm{L}$. The pathological interaction between malaria and HIV in dually infected patients is synergistic and bidirectional [13]. Malaria leads to an increase in HIV viral load and a decline in $\mathrm{CD} 4+\mathrm{T}$ cell count. Malaria also increases the rate of disease progression from HIV infection to acquired immunodeficiency syndrome. Conversely, HIV contributes to more frequent and more severe malaria infections [14], and an increased risk of congenital infection among pregnant women. People with malaria- HIV coinfection are more likely to harbor parasites at a high density $[15,16]$. Immunologically, malaria and HIV both interact with the host's immune system, leading to complex activation of immune cells and the production of cytokines and antibodies [17]. Therapeutically, HIV impairs the efficacy of antimalarial treatments and may increase adverse events.

Epidemiological studies on the association of malariaHIV coinfection with anemia in pregnancy are not population-based and suffer from low statistical precision $[18,19]$. Therefore, we conducted a large-scale population-based cross-sectional study to explore the association of malaria, HIV and malaria- HIV coinfection, with anemia in pregnancy in sub-Saharan African countries using the most recent Demographic and Health Surveys (DHS) data from 2012 to 2017, and hypothesized that malaria, HIV and malaria- HIV coinfection is associated with anemia in pregnancy in sub-Saharan Africa. A deeper understanding of the epidemiology of the two prevalent and major infections in sub-Saharan Africa and their possible joint effect in contributing to anemia in pregnancy is critical for guiding preventative, control, and treatment strategies to improve fetal, perinatal, and maternal health.

\section{Methods}

Data sources and participants

Data were from the latest Demographic and Health Surveys from 7 sub-Saharan Africa countries: Burundi, 
the Democratic Republic of the Congo, Ghana, The Gambia, Mali, Senegal, and Togo (Additional File 1). The data were collected by each country and coordinated by ICF in Rockville, Maryland, USA [20], a global consulting and technology services company that conducts the Demographic and Health Survey funded by the United States Agency for International Development. The survey collected nationally representative health data to monitor and evaluate population health and nutrition programs. The details of sampling methods are discussed elsewhere. (https://dhsprogram.com/WhatWe-Do/Survey-Types/DHS-Methodology.cfm). In summary, data collection was based on a stratified two-stage probability sampling design, with the samples drawn from the most recent census frame, which is the sampling frame. First, countries were divided into geographic regions. Within these regions, populations were stratified by urban and rural areas of residence. The DHS surveys never define the urban/rural, it always follows the national definition which was defined by the population census. Within these stratified areas, a random selection of enumeration areas (EAs) or primary sampling units (PSUs) were drawn. On average, surveys selected 300-500 EAs with probability proportional to the population [20]. In the second stage of sampling, all households within a PSU were listed from the most recent population census and $\sim 30$ households per PSU were randomly selected for an interview with the use of equal probability systematic sampling. For each sampled household, women between the ages of 15 and $49 \mathrm{y}$ were sampled. Blood samples were collected from women for laboratory testing of malaria, HIV, and hemoglobin concentration as detailed below.

\section{Ethical considerations}

Each country's DHS protocols and guidelines, including biomarker collection, were reviewed and approved by their respective Ethical Review Committee and the Institutional Review Board of ICF, USA. Written informed consent was obtained from each participant before the survey. The DHS Program permitted the authors to use the data. The data are entirely anonymous; therefore, the authors did not seek further ethical clearance.

\section{Assessment of hemoglobin concentration and anemia (outcome)}

Blood samples were obtained from a drop of blood taken from a finger prick. A drop of blood from the prick site was drawn into a microcuvette, and hemoglobin analysis was carried out on-site with a battery-operated portable HemoCue analyzer (HemoCue AB, Angelhom, Sweden). Hemoglobin concentrations adjusted for altitude and cigarette smoking status using formulae provided by the US Centers for Disease Control and Prevention [21-23].
Hemoglobin concentration was categorized into anemia levels using World Health Organization standards [24]: severe (hemoglobin concentration $<70 \mathrm{~g} / \mathrm{L}$ ), moderate (hemoglobin concentration is between 70 to $99 \mathrm{~g} / \mathrm{L}$ ), mild (hemoglobin concentration is between $100 \mathrm{~g} / \mathrm{L}$ and $109 \mathrm{~g} / \mathrm{L}$ ) or any anemia (hemoglobin concentration is < $110 \mathrm{~g} / \mathrm{L}$ ). Respondents received the results of the anemia test immediately, as well as information on how to prevent anemia. Pregnant women with a hemoglobin concentration of $<70 \mathrm{~g} / \mathrm{L}$ were referred for follow-up care to a local health clinic.

\section{Exposure and covariates}

The primary exposure variables of interest were malaria, HIV and malaria- HIV coinfection. Malaria testing was carried out using SD Pf/Pan Rapid diagnostic tests, Bioline Malaria Ag P.f/Pan (Abbot, Standard Diagnostics, Inc., Gyeonggi-do, and Republic of Korea) which is a qualitative test for the detection of histidine-rich protein II antigen of Plasmodium falciparum (Pf), Plasmodium vivax (Pv) and other malaria species in human whole blood. HIV testing was carried out using the standard testing algorithm of HIV antibody enzyme-linked immunosorbent assays (ELISAs) [25]:: First assay test, Vironostika ${ }^{\circ} \mathrm{HIV}$ Ag/Ab (Biomérieux) ELISA was used. All positives results were subjected to a second ELISA, the Enzygnost ${ }^{\circ}$ HIV Integral II assay (Siemens). For discordant results, the InnoLia HIV I/II Score (Innogenetics, Ghent, Belgium), was used as a third confirmatory blot assay.

Possible confounders adjusted for were: age, iron supplementation, pregnancy trimesters and intermittent preventative therapy use.

\section{Statistical analysis}

We assumed intra-country and intra-PSU correlation among the responses. Therefore, we fit generalized linear mixed-effects models (GLMM) using the lme4 package in $\mathrm{R}$ version 3.5.1 [26]. For the binary outcome of anemia (1/0), we used binomial-distributed errors with log link function whereas Gaussian error model and an identity link function was used for average hemoglobin concentration. We employed a log-binomial as opposed to log-odds function to avoid overestimating the prevalence ratio of infection-anemia association due to the high prevalence of anemia in our study population (48\%). We accounted for two random effects with PSU nested with country. With the inclusion of country and PSU random effects, we accounted for observable and unobservable factors specific to individuals within a country and PSU such as environmental factors (rainfall, temperature, and altitude) and access to food, which potentially influence hemoglobin concentration [27]. We examined the association of malaria, HIV, and malariaHIV coinfection, with anemia and hemoglobin 
concentration in pregnancy using two models. First, in the unadjusted model in which we modeled the association of infection status and anemia status $(\mathrm{Hb}<110 \mathrm{~g} /$ L). In the second model, a multivariable-adjusted model, we adjusted for the potential confounders listed above. We reported the unadjusted and adjusted prevalence ratios (PR) and 95\% confidence intervals for anemia and other covariates included in the model [28]. Also, we reported the estimated means of hemoglobin concentration and the $95 \%$ confidence intervals. In both models, we accounted for the random effects of the country and the PSU. We carried out a sensitivity analysis by examining the association of infection status and lower threshold of hemoglobin concentration of $<100 \mathrm{~g} / \mathrm{L}$. The analyses were weighted using poststratification fractions defined based on the 2017 population size of the 7 countries. For all the analyses, the significance level was set at $\alpha<0.05$. All analyses were performed with $R$ statistical language ( $R$ Development Core Team 2017) [29] and map created using ArcGIS version 10.4.1 for desktops (Environmental Systems Research Institute (ESRI), USA.

\section{Results}

\section{Sample description}

The flow of study sample selection is shown in Fig. 1. Data were collected between November 2012 and December 2017. Detailed in Additional File 1 is a list of the surveys. The sample consisted of 947 pregnant women between the ages of 15-49years old from 7 different countries (Burundi, the Democratic Republic of the Congo, Gambia, Ghana, Mali, Senegal and Togo). The mean (SD) age of the respondents was 29 (6) years, and half were taking intermittent preventive treatment using sulfadoxine/pyrimethamine (Table 1). The proportion of respondents who owned an insecticide treated net was 93\% among the overall population. Of all survey respondents, $63 \%$ had no formal education, regardless of anemia status, and $67 \%$ were from rural residencies. The prevalence of anemia was higher among participants who are adherent to iron supplementation ( $55 \%$ vs. $46 \%, p=0.01$ ) and in those who were on intermittent preventive treatment with sulfadoxine/pyrimethamine ( $53 \%$ vs. $44 \%, p=0.03$ ). Western African countries had higher prevalence of anemia compared to Central and East African countries. No differences in household wealth quintile status, marital status, breast feeding status and number of births in the previous 5 years. Figure 2 displays the spatial distribution of hemoglobin concentration for clusters sites included in the analysis. In Western Africa, the geographical distribution of low hemoglobin concentration was heterogeneous and was present in large clusters. In Eastern Africa (Burundi), and Central Africa (the Democratic Republic of the Congo), low hemoglobin concentration was homogenously across the region. Figure 3 shows the median (50th

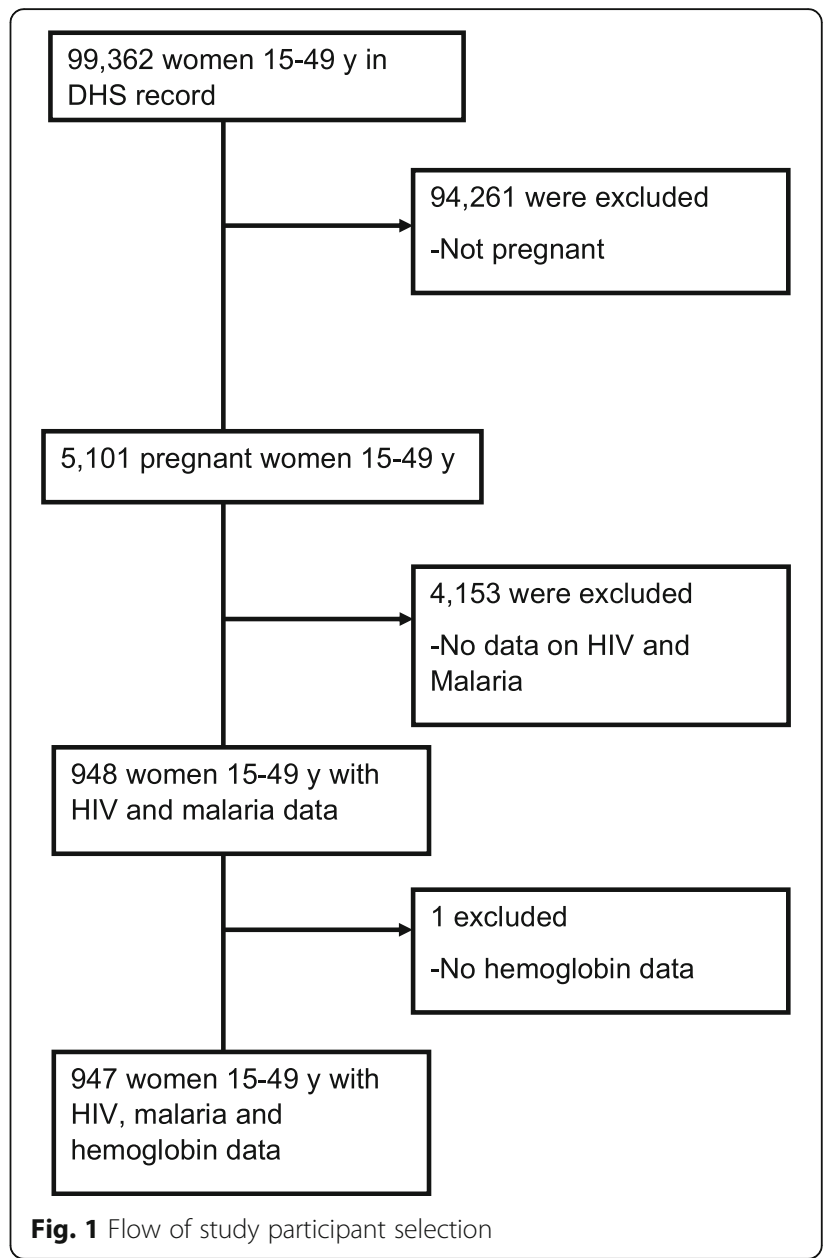

percentile), 25th and 75th percentiles of hemoglobin concentration by infection status (A), pregnancy trimester (B), antenatal care attendance $(C)$, household wealth index quintiles (D), countries (E), and age group (F). The overall prevalence of malaria infection only, HIV only and malaria- HIV coinfection was $31 \%$ (95\% CI: 28.5 to $34.5 \%, n=$ 293), $1.3 \%$ (95\% CI: 0.77 to $2.4 \%, n=13)$ and $0.52 \%(95 \%$ CI: 0.02 to $1.3 \%, n=5)$ respectively. The prevalence of malaria in HIV positive pregnant women was 38\% (95\% CI: 15 to 68\%). Prevalence of any anemia and moderate anemia was higher in pregnant women with malaria and HIV infections than in pregnant women without infections. Mild and severe anemia prevalence was not significantly different across the infection categories (Table 2).

\section{Association between the infection status and anemia in pregnancy}

Table 3 shows the unadjusted and adjusted PRs of the association between infection categories and anemia in pregnant women. In model adjusted only for country and PSU random effects (unadjusted model), malaria, HIV and malaria- HIV coinfection were associated with 
Table 1 Background characteristics of the survey participants

\begin{tabular}{|c|c|c|c|c|}
\hline Characteristics & $\begin{array}{l}\text { All participants } \\
(\boldsymbol{n}=947), \text { No. (\%) }\end{array}$ & $\begin{array}{l}\text { Anemia }=\text { Yes } \\
(\boldsymbol{n}=458), \text { No. }(\%)\end{array}$ & $\begin{array}{l}\text { Anemia }=\text { No } \\
(\boldsymbol{n}=489), \text { No. }(\%)\end{array}$ & $p$-value \\
\hline Age, mean (SD), y & $28.8(5.9)$ & $29.0(6.0)$ & $29.1(5.8)$ & 0.1202 \\
\hline Age Categories (y) & & & & 0.6406 \\
\hline $15-19$ & $34(4)$ & $20(59)$ & $14(41)$ & \\
\hline $20-24$ & $204(22)$ & $105(51)$ & $99(49)$ & \\
\hline $25-29$ & $288(30)$ & $140(49)$ & $148(55)$ & \\
\hline $30-34$ & $253(27)$ & $115(45)$ & $138(55)$ & \\
\hline $35-39$ & $120(4)$ & $53(44)$ & $67(56)$ & \\
\hline $40-44$ & $42(4)$ & $22(52)$ & $20(48)$ & \\
\hline $45-49$ & $6(1)$ & $3(50)$ & $3(50)$ & \\
\hline Malaria & & & & 0.0014 \\
\hline Positive & $298(31)$ & $167(56)$ & $131(44)$ & \\
\hline Negative & $649(69)$ & $291(45)$ & $358(55)$ & \\
\hline HIV infection status & & & & 0.3385 \\
\hline Positive & $13(1)$ & $8(62)$ & $5(38)$ & \\
\hline Negative & 934 (99) & $450(48)$ & $484(52)$ & \\
\hline Malaria-HIV Category & & & & 0.001 \\
\hline Malaria only & $293(31)$ & $164(56)$ & $129(44)$ & \\
\hline HIV only & $8(0.8)$ & $5(62.5)$ & $3(37.5)$ & \\
\hline Malaria-HIV coinfection & $5(0.5)$ & $3(60)$ & $2(40)$ & \\
\hline No infection & $641(68)$ & $286(45)$ & $355(55)$ & \\
\hline Hemoglobin mean (SD), g/L, & $11.0(1.7)$ & $9.7(1.2)$ & $12.2(1.0)$ & $<0.0001$ \\
\hline Insecticide Treated Nets & & & & 0.8073 \\
\hline Yes & $503(93)$ & $249(49.5)$ & $254(50.5)$ & \\
\hline No & $40(7)$ & $19(47.5)$ & $21(52.5)$ & \\
\hline Intermittent Preventive Treatment & & & & 0.003 \\
\hline Yes & $453(48)$ & $242(53)$ & $211(47)$ & \\
\hline No & $487(52)$ & $213(44)$ & $274(56)$ & \\
\hline Education level & & & & 0.55 \\
\hline No formal schooling & $348(37)$ & $175(50)$ & $173(50)$ & \\
\hline Primary & $322(34)$ & $159(49)$ & $163(51)$ & \\
\hline Secondary & $261(28)$ & $117(45)$ & $144(55)$ & \\
\hline More than secondary & $16(2)$ & $7(44)$ & $9(56)$ & \\
\hline Household wealth quintile & & & & 0.43 \\
\hline Lowest & $210(22)$ & $110(52)$ & $100(48)$ & \\
\hline Second & $180(19)$ & $90(50)$ & $90(50)$ & \\
\hline Middle & $189(20)$ & $86(45.5)$ & $103(54.5)$ & \\
\hline Fourth & $183(19)$ & $91(50)$ & $92(50)$ & \\
\hline Highest & $185(20)$ & $81(44)$ & $104(56)$ & \\
\hline Place of residence & & & & 0.35 \\
\hline Urban & $316(33)$ & $146(46)$ & $170(54)$ & \\
\hline Rural & $631(67)$ & $312(49)$ & $319(51)$ & \\
\hline Iron Supplementation & & & & 0.01 \\
\hline Less than 90 days & $714(75)$ & $329(46)$ & $385(54)$ & \\
\hline
\end{tabular}


Table 1 Background characteristics of the survey participants (Continued)

\begin{tabular}{|c|c|c|c|c|}
\hline Characteristics & $\begin{array}{l}\text { All participants } \\
(\boldsymbol{n}=947), \text { No. (\%) }\end{array}$ & $\begin{array}{l}\text { Anemia }=\text { Yes } \\
(\boldsymbol{n}=458), \text { No. }(\%)\end{array}$ & $\begin{array}{l}\text { Anemia }=\text { No } \\
(\boldsymbol{n}=489), \text { No. }(\%)\end{array}$ & $\boldsymbol{p}$-value \\
\hline Equal to or greater than 90 days & $233(25)$ & $129(55)$ & $104(45)$ & \\
\hline Marital Status & & & & 0.13 \\
\hline Not married & $9(1)$ & $2(22)$ & $7(78)$ & \\
\hline Married & $913(96)$ & $447(49)$ & $466(51)$ & \\
\hline Divorced & $25(3)$ & $9(36)$ & $16(64)$ & \\
\hline Births in the last 5 years & & & & 0.88 \\
\hline 2 or less & $913(96)$ & $442(48)$ & $471(52)$ & \\
\hline More than 2 & $34(4)$ & $16(47)$ & $18(53)$ & \\
\hline Currently Breastfeeding status & & & & 0.96 \\
\hline Yes & $105(11)$ & $51(49)$ & $54(51)$ & \\
\hline No & $842(89)$ & $407(48)$ & $435(52)$ & \\
\hline Country & & & & 0.0007 \\
\hline Burundi & $246(26)$ & $103(42)$ & $143(58)$ & \\
\hline The Democratic republic of the Congo & $302(32)$ & $127(42)$ & $175(58)$ & \\
\hline Ghana & $107(11)$ & $58(54)$ & $49(46)$ & \\
\hline The Gambia & $49(5)$ & $31(63)$ & $18(37)$ & \\
\hline Mali & $88(9)$ & $50(57)$ & $38(43)$ & \\
\hline Senegal & $71(8)$ & $38(54)$ & $33(46)$ & \\
\hline Togo & $84(9)$ & $51(61)$ & $33(39)$ & \\
\hline
\end{tabular}

26, 42 and 36\% higher prevalence of anemia compared to uninfected pregnant women. In model adjusted for a full set of covariates (adjusted model) and country and PSU random effects, malaria was associated with $27 \%$ higher prevalence of anemia, HIV with $41 \%$ higher prevalence of anemia, and malaria- HIV coinfection was associated with $22 \%$ higher prevalence of anemia than pregnant women without either infection. In the fully adjusted model, anemia prevalence was higher in the second and third trimesters than in the reference category of pregnant women in the first trimester. Malaria and HIV infections explained $6 \%$ of the variance in anemia and hemoglobin concentration.

In Table 4, we report estimated means results of hemoglobin concentration $(\mathrm{g} / \mathrm{L})$ as a continuous dependent variable. Compared to the participants without any infections, malaria infection was associated with a $3.4 \mathrm{~g} / \mathrm{L}$ lower hemoglobin $(95 \% \mathrm{CI}$ - 5.01 to -1.79 ; $p=0.03$, Fig. 3a). Results for HIV and malaria- HIV coinfection were nonsignificant $(p=0.84$, and $p=0.35$ respectively). Compared to the first trimester $(n=277)$, the mean hemoglobin concentration was lower in participants in the second $(n=369)$ and third trimester $(n=$ 301) (Fig. 3b). In a sensitivity analysis examining the association of infection status and lower threshold of hemoglobin concentration of $<100 \mathrm{~g} / \mathrm{L}$, the results are consistent with the primary model and are reported in Additional File 2.

\section{Discussion}

We showed that malaria infection had a significant association with anemia and lower hemoglobin concentration in pregnancy. The finding was robust to adjustment for various confounding factors. The absence of any association for HIV and malaria-HIV coinfection is possibly due to low statistical precision. The quantitatively small variation of $6 \%$ in hemoglobin concentrations and anemia explained by malaria and HIV infections shown in our analysis suggests that in sub-Saharan Africa, anemia in pregnancy is a result of a complex interplay of other factors in addition to malaria and HIV. Such factors include; nutritional (such as iron and folate deficiency) and genetics (such as inherited hemoglobin disorders) and inflammation [4, 30-32].

The high prevalence of anemia in pregnant women was consistent with a previously reported prevalence of $56 \%$ in studies of the same region [1]. The association of anemia in pregnant women with either HIV or malaria separately or both has been reported in smaller studies (and reviews) in Africa [33, 34]. The lack of a significant association with HIV and malaria-HIV coinfection should be interpreted with caution. Due to lower numbers in these groups, the standard errors were large providing a wide confidence interval. However, the malariaHIV coinfection group had the lowest point estimates of hemoglobin concentration compared to either malaria or HIV infection alone, suggesting a possible joint effect 


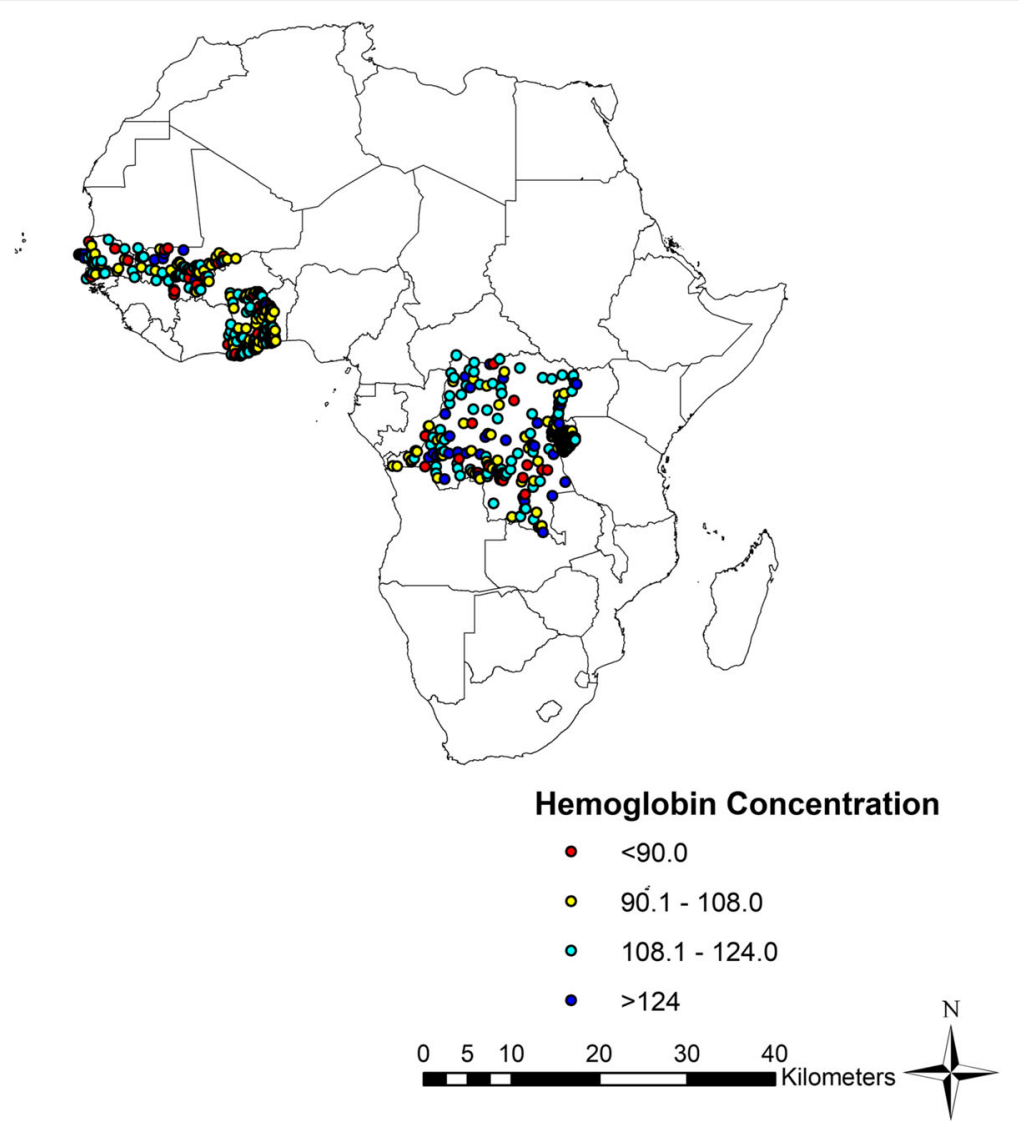

Fig. 2 Spatial distribution of hemoglobin concentration for clusters sites (primary sampling units) included in the analysis. Map produced using ArcGIS version 10.4.1 (ESRI, Redlands, CA, United States of America)

between malaria and HIV (Fig. 3 A). The prevalence of malaria in HIV infected pregnant women was 7 percentage points higher than in the pregnant women without HIV infection. This is agreement with a prospective study in South Africa, in which HIV-infected adults were at increased risk of severe malaria [35].

The mechanisms by which malaria and HIV lead to anemia in pregnancy are complex. Malaria infection during pregnancy causes acute anemia mainly through direct destruction of erythrocytes, sequestration of infected and uninfected erythrocytes by the spleen, and decreased erythropoiesis. Furthermore, the placental sequestration of malaria-infected erythrocytes is typical in pregnant women [36], and occurs in the intervillous space. Placental sequestration is aided by placental adhesion molecules particularly chondroitin sulfate A [37] which interacts with the Plasmodium falciparum erythrocytes membrane protein-1,VAR2CSA [38]. Hepcidin, the master regulator of bioavailable iron and a key mediator of anemia, is elevated in placental-malaria [39, 40]. In addition to increasing the susceptibility of pregnant women to anemia, hepcidin is causally associated with anemia or lower hemoglobin concentration in the offspring [40], suggestion long-term effects of malaria in pregnancy in infants. The resultant mechanical vascular blockage by placental sequestration impairs placental blood flow to the fetus, consequently increasing the risk of intrauterine growth restriction and fetal demise [38]. On the other hand, HIV in pregnancy leads to chronic anemia, which develops as a result of HIV-induced inflammation, reduced food intake, and impaired iron absorption caused by antiretroviral therapy [41].

Preventative strategies for anemia in pregnancy due to malaria and HIV are well documented. The current guidelines for the management of HIV in pregnant women include the use of trimethoprim-sulfamethoxazole (co-trimoxazole) in addition to antiretroviral therapy, which both lower odds of coinfection [42]. In a prospective study in Uganda, a combination of co-trimoxazole, antiretroviral therapy, and insecticide-treated bednets substantially reduced the frequency of malaria in adults with HIV [43]. Malaria control in pregnant women can be achieved chiefly by vector control using insecticide treated bednets, residual spraying and use of intermittent preventive treatment in pregnancy with sulfadoxine/pyrimethamine. Unexpectedly however, in our study, intermittent 


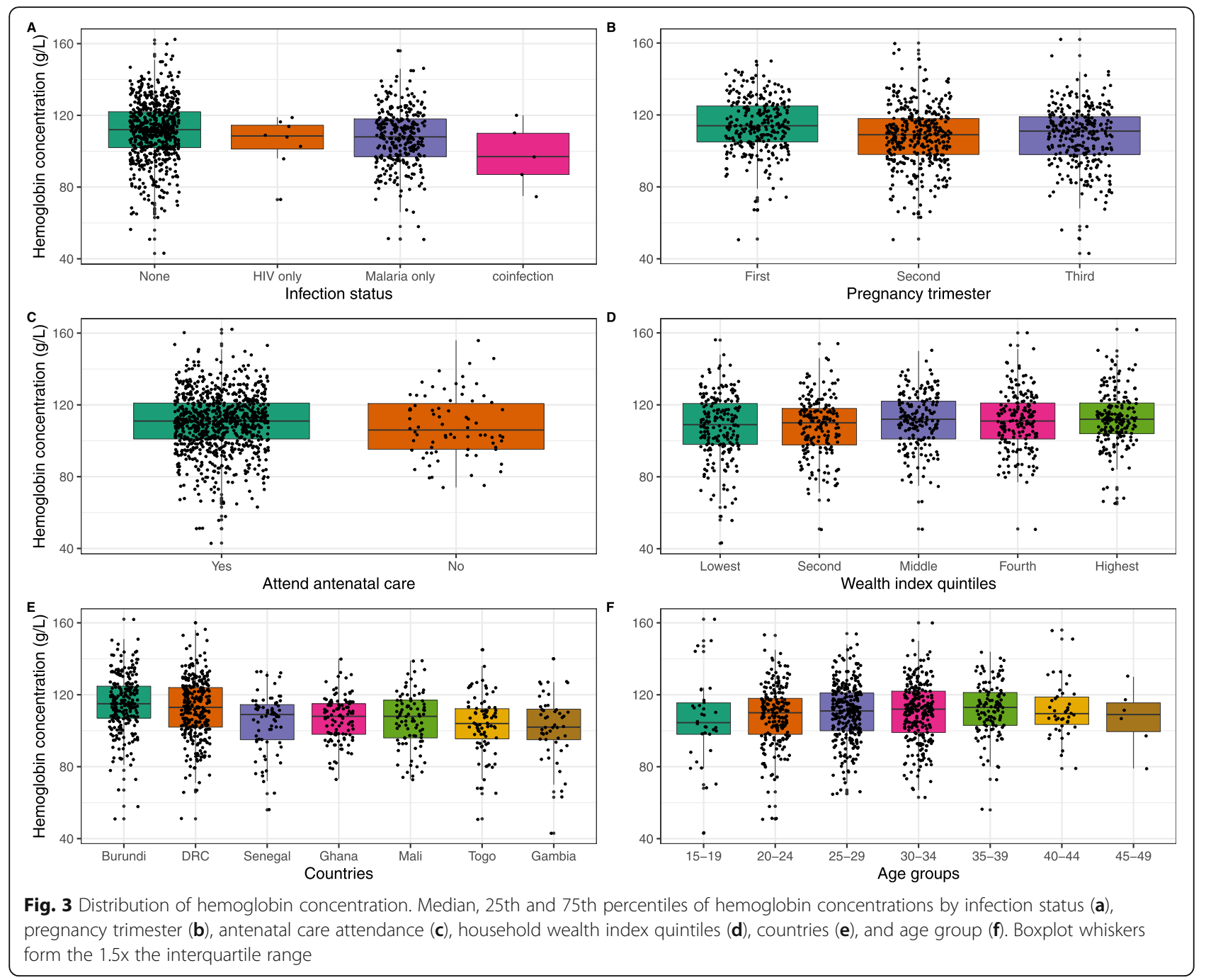

preventive treatment with sulfadoxine/pyrimethamine was associated with deleterious effects on maternal hemoglobin. Such a finding could be explained by increasing parasite resistance in various parts of sub-Saharan Africa resulting to the effect of IPTp transitioning from net benefit to neutral or net harm [44]. There is however a dilemma of using intermittent preventive treatment in pregnant women who are on antiretroviral therapy and cotrimoxazole prophylaxis for opportunistic infections due to the risk of sulfonamide-induced adverse drug reactions. Therefore, intermittent preventive treatment is contraindicated in this group (see an excellent review by Tebit Kwenti) [13].

Although we observed an association between malaria infection and anemia in pregnancy, the variance in hemoglobin concentration and anemia explained by this association was small (6\%), suggesting that other factors other than malaria are attributable to the high

Table 2 Estimated percentages and 95\% confidence interval of distribution of outcome variables across exposure categories

\begin{tabular}{llllll}
\hline Anemia severity group \% (95\% Cl) & $\begin{array}{l}\text { Total } \\
\mathrm{n}=947\end{array}$ & $\begin{array}{l}\text { No infection } \\
\boldsymbol{n}=641\end{array}$ & $\begin{array}{l}\text { Malaria only } \\
\mathrm{n}=293\end{array}$ & $\begin{array}{l}\text { HIV only } \\
\boldsymbol{n}=8\end{array}$ & Malaria- HIV coinfection, $\mathrm{n}=5$ \\
\hline Any Anemia & $48(46-52)$ & $45(41-49)$ & $56(50-62)$ & $63(26-90)$ & $60(17-93)^{\mathrm{a}}$ \\
Mild & $23(20-25)$ & $21.8(19-25)$ & $25(20-30)$ & $38(10-74)$ & $0(0-54)$ \\
Moderate & $24(21-27)$ & $20(17-23)$ & $29(24-35)$ & $25(5-65)$ & $60(18-92)^{\mathrm{a}}$ \\
Severe & $2(1-3)$ & $2.0(0.8-2.9)$ & $2(1-4)$ & $0.0(0-0.4)$ & $0.0(0-54)$ \\
\hline
\end{tabular}

HIV Human Immunodeficiency Virus

${ }^{a}$ Proportions in the 4 groups were significantly different from each other, $P<0.05$ (Fisher Exact probability test) 
Table 3 Unadjusted and multivariable-adjusted prevalence ratio (95\% confidence interval) for the association of infection status with anemia $(\mathrm{Hb}<110 \mathrm{~g} / \mathrm{L})$ in pregnant women, $15-49$ y old ${ }^{\mathrm{a}}$

\begin{tabular}{|c|c|c|c|c|}
\hline & Unadjusted PR (95\% Cl) & $p$-value & Adjusted PR (95\% Cl) & $\boldsymbol{p}$-value \\
\hline \multicolumn{5}{|l|}{ Infection status } \\
\hline Malaria only & $1.26(1.12-1.45)$ & 0.0006 & $1.27(1.12-1.45)$ & 0.0004 \\
\hline HIV only & $1.42(0.80-2.41)$ & 0.20 & $1.41(0.83-2.41)$ & 0.21 \\
\hline Malaria- HIV coinfection & $1.36(0.66-2.74)$ & 0.40 & $1.22(0.61-2.46)$ & 0.58 \\
\hline No infection & Reference & & Reference & \\
\hline
\end{tabular}

${ }^{a}$ Associations were estimated with the use of generalized linear mixed-effects models (binomial-distributed errors with log link function). All values are PRs (95\% Cls)

prevalence of anemia in pregnant women. In subSaharan Africa, low hemoglobin concentration is also caused by nutritional deficiencies of iron [45], vitamin B12 and folate [46]; genetic traits such as sickle cell trait [32]; parasitic infections such as hookworm infection [47], and schistosomiasis [48] and should be explored in pregnant women presenting with anemia. Intervention studies demonstrate the positive effect of iron supplementation on hemoglobin concentrations in those with anemia, both in pregnant [49] and non-pregnant women $[50,51]$. However, in our analysis, adherence to iron supplementation (defined as using iron supplementation for $\geq 90 \mathrm{~d}$ during pregnancy) was low at $25 \%$, consistent with our recent findings [51], and was not significantly associated with protection against anemia in pregnancy.

Factors contributing to the mean hemoglobin differences between the Western region and the rest of subSaharan Africa have been explored. Geospatial analysis of hemoglobin concentration in sub-Saharan Africa concluded that known environmental drivers of anemiacausing parasitic infections and nutritional iron deficiency, such as distance to a perennial water body, land surface temperature and normalized difference vegetation index show stronger effects for Western Africa than Eastern Africa [27]. In addition, inherited hemoglobin disorders particularly in Western Africa, could, in part, account for the difference anemia variation between Western and Central and East Africa [32].

Our study had some limitations. First, the crosssectional nature of the study could not allow us to infer causality. Anemia is a chronic multifactorial syndrome and women are often anemic before becoming pregnant. Therefore, the temporal association between malaria during pregnancy and anemia occurrence could not be established in our study. Second, a onetime assessment of malaria and HIV in this cross-sectional study design could have led to an underestimation of the infection rate since infection testing was not repeated. Third, pregnancy is self-reported hence early pregnancy is likely to be under reported. The pregnancy reporting behavior from the DHS data shows that only $75 \%$ of women with a 10-week pregnancy report that they are pregnant. Fourth, variable selection for the infection-anemia models was mainly driven by information availability from the survey datasets. Consequently, other possible confounding variables such as gestational age, nutritional status (pre-pregnancy BMI, gestational weight gain) and helminths that were not adjusted in our analysis could have biased the observed association. Nevertheless, considering we adjusted for major possible confounders known to be associated with malaria and HIV and anemia, our study provides stable estimates of anemia in pregnancy in several countries in sub-Saharan Africa using a nationally representative sample. Such factors include pregnancy trimester, iron supplementation, and intermittent malaria preventive treatment use. Lastly, our study had low number of coinfected pregnant women resulting in excessively wide confidence intervals. The low prevalence of $1.3 \%$ in the study population is explained by the low prevalence of HIV in Western, Central and Eastern Africa, which represents our study sample. It is likely such a selection bias could have

Table 4 Associations between the infection status and anemia in pregnant women, 15-49 y old with the hemoglobin concentration (in $\mathrm{g} / \mathrm{L}$ ) as continuous dependent variables ${ }^{\mathrm{a}}$

\begin{tabular}{llll}
\hline Infection status & Adjusted estimated hemoglobin means (95\% Cl) & estimates (SE) & p-value \\
\hline Malaria only & $106(100.1$ to 113$)$ & $-3.4(1.6)$ & $-1.2(6.1)$ \\
HIV only & $109(95.4$ to 122$)$ & $-8.1(8.7)$ & 0.84 \\
Coinfection & $102(83.7$ to 120$)$ & Reference
\end{tabular}

${ }^{a}$ Associations were estimated with the use of generalized linear mixed-effects models (Gaussian error model and an identity link function). $95 \%$ of SEs were clustered by country and primary sampling units. Adjusted for age, trimesters and iron supplementation 
influenced the estimates towards the null. Consequently, our findings may not generalize to entire sub-Saharan Africa.

\section{Conclusion}

Malaria was associated with an increased prevalence of anemia during pregnancy. The prevalence of HIV infection and malaria-HIV coinfection was too low to allow meaningful analysis of their association with anemia or hemoglobin concentration.

\section{Supplementary information}

Supplementary information accompanies this paper at https://doi.org/10. 1186/s12884-020-03064-X.

Additional File 1. Country- specific sample size and population. Sample size summary for the analyzed DHS data indicating the country, year of survey, number of pregnant women, region and 2017 population size.

Additional File 2. Sensitivity analysis. Association of infection status with anemia $(\mathrm{Hb}<100 \mathrm{~g} / \mathrm{L})$ in pregnant women, 15-49 y old.

\section{Abbreviations}

HIV: Human immunodeficiency virus; DHS: Demographic and health survey; USAID: United States Agency for International Development; PR: Prevalence Ratio; Hb: Hemoglobin

\section{Acknowledgments}

The authors thank the DHS program for its support and free access to the original data.

\section{Authors' contributions}

PS has full access to all of the data in the study and takes responsibility for the integrity of the data and the accuracy of the data analysis. Concept and design: PS, DMB, AES, DL, VMC. Data acquisition, analysis and interpretation: PS, DMB, AES, JEE, MW, VMC. Writing the manuscript: PS. Statistical analysis: PS, DMB, MW, DL, VMC. Supervision: VMC. All authors read and approved the final version of this manuscript.

\section{Funding}

The author(s) received no specific funding for this work.

\section{Availability of data and materials}

The data sets were accessed after obtaining permission from Measure DHS. Data sets under the project Malnutrition in Africa. The analyzed dataset is available from: https://dhsprogram.com/data/available-datasets.cfm. Data is available for download from the website after acquiring permission from Measure DHS. We confirm that we did not have special access privileges to this data.

\section{Ethics approval and consent to participate}

The DHS program takes strict measures for protecting the privacy of all survey respondents. Procedures and questionnaires for standard DHS surveys have been reviewed and approved by the ICF International Institutional Review Board (IRB) and the IRB of the host country. ICF International IRB ensures that the survey complies with the U.S. ICF International provides both writing and oral informed consent to each survey respondent before the beginning of each survey question and biomarker tests. Each participant's participation was voluntary. We obtained permission from Measure DHS to access the data and use it for our research.

\section{Consent for publication}

No consent to publish was needed for this study as we did not use any details, images or videos related to individual participants.

\section{Competing interests}

The authors have declared that no competing interests exist.

\section{Author details}

${ }^{1}$ Center for Neural Engineering, Department of Engineering, Science and Mechanics, Penn State University, University Park, PA, USA. ²Department of Public Health Sciences, Penn State College of Medicine, Hershey, PA, USA.

${ }^{3}$ Center for Applied Studies in Health Economics, Penn State College of Medicine, Hershey, PA, USA. ${ }^{4}$ Department of Pediatrics, Penn State College of Medicine, Hershey, PA, USA.

Received: 3 January 2020 Accepted: 17 June 2020

Published online: 29 June 2020

\section{References}

1. Stevens GA, Finucane MM, De-Regil LM, Paciorek CJ, Flaxman SR, Branca F, Peña-Rosas JP, Bhutta ZA, Ezzati M, Group NIMS. Global, regional, and national trends in haemoglobin concentration and prevalence of total and severe anaemia in children and pregnant and non-pregnant women for 1995-2011: a systematic analysis of population-representative data. Lancet Glob Health. 2013;1(1):e16-25.

2. Rukuni R, Bhattacharya S, Murphy MF, Roberts D, Stanworth SJ, Knight M. Maternal and neonatal outcomes of antenatal anemia in a Scottish population: a retrospective cohort study. Acta Obstet Gynecol Scand. 2016; 95(5):555-64.

3. McLean E, Cogswell M, Egli I, Wojdyla D, De Benoist B. Worldwide prevalence of anaemia, WHO vitamin and mineral nutrition information system, 1993-2005. Public Health Nutr. 2009;12(4):444-54.

4. World Health Organization: World malaria report 2019. 2019.

5. Eaton JW, Rehle TM, Jooste S, Nkambule R, Kim AA, Mahy M, Hallett TB. Recent HIV prevalence trends among pregnant women and all women in sub-Saharan Africa: implications for HIV estimates. AIDS (London, England). 2014;28(4):S507.

6. Dwyer-Lindgren L, Cork MA, Sligar A, Steuben KM, Wilson KF, Provost NR, Mayala BK, VanderHeide JD, Collison ML, Hall JB. Mapping HIV prevalence in sub-Saharan Africa between 2000 and 2017. Nature. 2019;570(7760):189-93.

7. De Beaudrap P, Turyakira E, White L, Nabasumba C, Tumwebaze B, Muehlenbachs A, Guérin PJ, Boum Y, McGready R, Piola P. Impact of malaria during pregnancy on pregnancy outcomes in a Ugandan prospectivecohort with intensive malaria screening and prompt treatment. Malar J. 2013;12(1): 139.

8. Ivan E, Crowther NJ, Mutimura E, Osuwat LO, Janssen S, Grobusch MP. Helminthic infections rates and malaria in HIV-infected pregnant women on anti-retroviral therapy in Rwanda. PLoS Negl Trop Dis. 2013;7(8):e2380.

9. Laar AK, Grant FE, Addo Y, Soyiri I, Nkansah B, Abugri J, Laar AS, Ampofo WK, Tuakli JM, Quakyi IA. Predictors of fetal anemia and cord blood malaria parasitemia among newborns of HIV-positive mothers. BMC research notes. 2013;6(1):350.

10. Organization WH: Malaria and HIV/AIDS interactions and implications: conclusions of a technical consultation convened by WHO, 23-25 June 2004. In: Malaria and HIV/AIDS interactions and implications: conclusions of a technical consultation convened by WHO, 23-25 June 2004. edn.; 2004.

11. González R, Ataíde R, Naniche D, Menéndez C, Mayor A. HIV and malaria interactions: where do we stand? Expert Rev Anti-Infect Ther. 2012;10(2): 153-65.

12. Njunda AL, Njumkeng C, Nsagha SD, Assob JCN, Kwenti TE. The prevalence of malaria in people living with HIV in Yaounde, Cameroon. BMC Public Health. 2016;16(1):964.

13. Kwenti TE. Malaria and HIV coinfection in sub-Saharan Africa: prevalence, impact, and treatment strategies. Research Reports Tropical Med. 2018;9:123.

14. Idemyor V. Human immunodeficiency virus (HIV) and malaria interaction in sub-Saharan Africa: the collision of two titans. HIV Clinical Trials. 2007;8(4): 246-53.

15. Abu-Raddad L, Patnaik P, Kublin JG. Dual infection with HIV and malaria fuels the spread of both diseases in sub-Saharan Africa. Science. 2006; 314(5805):1603-6.

16. Chijioke-Nwauche IN: Use of artemether-lumefantrine in the treatment of asymptomatic-malaria infection in HIV-positive and HIVnegative Nigerian adults. London School of Hygiene \& Tropical Medicine; 2014.

17. Renia L, Potter S. Co-infection of malaria with HIV: an immunological perspective. Parasite Immunol. 2006;28(11):589-95.

18. Van Eijk AM, Ayisi JG, Ter Kuile FO, Misore AO, Otieno JA, Rosen DH, Kager PA, Steketee RW, Nahlen BL. HIV increases the risk of malaria in women of all gravidities in Kisumu, Kenya. Aids. 2003;17(4):595-603. 
19. Nkuo-Akenji T, Tevoufouet EE, Nzang F, Fon E, Ebong IN. HIV/AIDS and malaria in pregnant women from Cameroon short running title: HIV, malaria in pregnancy. Afr J Health Sci. 2011;18:105-9.

20. Measure D. ICF international. Demographic and Health Surveys methodology: Sampling and household listing manual Calverton. ICF International: MD; 2012.

21. Prevention C: CfDCa. Recommendations to prevent and control iron deficiency in the United States. In.: MMWR; 1998.

22. Control CfD. CDC criteria for anemia in children and childbearing-aged women. MMWR Morb Mortal Wkly Rep. 1989;38(22):400.

23. Sullivan KM, Mei Z, Grummer-Strawn L, Parvanta I. Haemoglobin adjustments to define anaemia. Tropical Med Int Health. 2008;13(10):1267-71.

24. Organization WH: Haemoglobin concentrations for the diagnosis of anaemia and assessment of severity. In: World Health Organization; 2011.

25. Mishra V, Vaessen M, Boerma J, Arnold F, Way A, Barrere B, Cross A, Hong R, Sangha J. HIV testing in national population-based surveys: experience from the demographic and health surveys. Bull World Health Organ. 2006;84:537-45.

26. McCulloch CE, Neuhaus JM. Generalized linear mixed models. Encyclopedia of biostatistics. 2005;4.

27. Magalhães RJS, Clements AC. Spatial heterogeneity of haemoglobin concentration in preschool-age children in sub-Saharan Africa. Bull World Health Organ. 2011;89:459-68.

28. Barros AJ, Hirakata VN. Alternatives for logistic regression in cross-sectional studies: an empirical comparison of models that directly estimate the prevalence ratio. BMC Med Res Methodol. 2003;3(1):21.

29. Team RC: R Core Team (2017). R: a language and environment for statistical computing. R Found Stat Comput Vienna, Austria URL http://www.R-project. org/, page R Foundation for Statistical Computing 2017.

30. Sifakis S, Pharmakides G. Anemia in pregnancy. Ann N Y Acad Sci. 2000; 900(1):125-36

31. Bashiri A, Burstein E, Sheiner E, Mazor M. Anemia during pregnancy and treatment with intravenous iron: review of the literature. Eur J Obstetrics Gynecol Reproductive Biol. 2003;110(1):2-7.

32. Weatherall D, Clegg JB. Inherited haemoglobin disorders: an increasing global health problem. Bull World Health Organ. 2001;79:704-12.

33. Steketee RW, Nahlen BL, Parise ME, Menendez C. The burden of malaria in pregnancy in malaria-endemic areas. Am J Tropical Med Hygiene. 2001; 64(1_suppl):28-35.

34. Ter Kuile FO, Parise ME, Verhoeff FH, Udhayakumar V, Newman RD, Van Eijk AM, Rogerson SJ, Steketee RW. The burden of co-infection with human immunodeficiency virus type 1 and malaria in pregnant women in subsaharan Africa. Am J Tropical Med Hygiene. 2004;71(2_suppl):41-54.

35. Cohen C, Karstaedt A, Frean J, Thomas J, Govender N, Prentice E, Dini L, Galpin J, Crewe-Brown H. Increased prevalence of severe malaria in HIVinfected adults in South Africa. Clin Infect Dis. 2005:41(11):1631-7.

36. Schantz-Dunn J, Nour NM. Malaria and pregnancy: a global health perspective. Rev Obstet Gynecol. 2009;2(3):186

37. Fried M, Domingo GJ, Gowda CD, Mutabingwa TK, Duffy PE. Plasmodium falciparum: chondroitin sulfate a is the major receptor for adhesion of parasitized erythrocytes in the placenta. Exp Parasitol. 2006;113(1):36-42.

38. Rogerson SJ, Hviid L, Duffy PE, Leke RF, Taylor DW. Malaria in pregnancy: pathogenesis and immunity. Lancet Infect Dis. 2007;7(2):105-17.

39. Muehlenbachs A, Fried M, Lachowitzer J, Mutabingwa TK, Duffy PE. Genomewide expression analysis of placental malaria reveals features of lymphoid neogenesis during chronic infection. J Immunol. 2007;179(1):557-65.

40. Brickley EB, Spottiswoode N, Kabyemela E, Morrison R, Kurtis JD, Wood AM, Drakesmith H, Fried M, Duffy PE. Cord blood hepcidin: cross-sectional correlates and associations with anemia, malaria, and mortality in a Tanzanian birth cohort study. Am J Tropical Med Hygiene. 2016;95(4):817-26.

41. Semba RD, Gray GE. Pathogenesis of anemia during human immunodeficiency virus infection. J Investig Med. 2001;49(3):225-39.

42. Zigah M. Prevalence and risk factors associated with malaria and Hiv coinfection among adult persons living with Hiv attending Margret Marquart Catholic Hospital. Kpando: University of Ghana; 2016

43. Mermin J, Ekwaru JP, Liechty CA, Were W, Downing R, Ransom R, Weidle P, Lule J, Coutinho A, Solberg P. Effect of co-trimoxazole prophylaxis, antiretroviral therapy, and insecticide-treated bednets on the frequency of malaria in HIV-1-infected adults in Uganda: a prospective cohort study. Lancet. 2006;367(9518):1256-61.

44. Harrington WE, Mutabingwa TK, Kabyemela E, Fried M, Duffy PE Intermittent treatment to prevent pregnancy malaria does not confer benefit in an area of widespread drug resistance. Clin Infect Dis. 2011;53(3): 224-30.

45. Stoltzfus RJ, Mullany L, Black RE. Iron deficiency anaemia. Comparative Quantification Health Risks. 2004;1:163-209.

46. Pena-Rosas JP, De-Regil LM, Gomez HM, Flores-Urrutia MC, Dowswell T: Intermittent oral iron supplementation during pregnancy. 2015.

47. Smith $J$ L, Brooker S. Impact of hookworm infection and deworming on anaemia in non-pregnant populations: a systematic review. Tropical Med Int Health. 2010;15(7):776-95.

48. King $\mathrm{CH}$, Dickman $\mathrm{K}$, Tisch DJ. Reassessment of the cost of chronic helmintic infection: a meta-analysis of disability-related outcomes in endemic schistosomiasis. Lancet. 2005;365(9470):1561-9.

49. Haider BA, Olofin I, Wang M, Spiegelman D, Ezzati M, Fawzi WW. Anaemia, prenatal iron use, and risk of adverse pregnancy outcomes: systematic review and meta-analysis. Bmj. 2013;346:f3443.

50. Fernández-Gaxiola AC, De-Regil LM. Intermittent iron supplementation for reducing anaemia and its associated impairments in menstruating women. Cochrane Database Syst Rev. 2011(12).

51. Ba DM, Ssentongo P, Kjerulff KH, Na M, Liu G, Gao X, Du P. Adherence to Iron Supplementation in 22 Sub-Saharan African Countries and Associated Factors among Pregnant Women: A Large Population-Based Study. Curr Developments Nutrition. 2019:3(12):nzz120.

\section{Publisher's Note}

Springer Nature remains neutral with regard to jurisdictional claims in published maps and institutional affiliations.
Ready to submit your research? Choose BMC and benefit from:

- fast, convenient online submission

- thorough peer review by experienced researchers in your field

- rapid publication on acceptance

- support for research data, including large and complex data types

- gold Open Access which fosters wider collaboration and increased citations

- maximum visibility for your research: over $100 \mathrm{M}$ website views per year

At BMC, research is always in progress.

Learn more biomedcentral.com/submissions 